\section{COLGATE ORAL HEALTH MONTH 2010 LAUNCHED}

At the British Dental Conference and Exhibition held in Liverpool in May this year, Colgate, in partnership with the British Dental Association (BDA), unveiled the 2010 Colgate Oral Health Month initiative.

Colgate Oral Health Month is a leading UK campaign for promotion of improved oral health. Its theme for 2010 is 'Discover 3 Essentials for an Even Healthier Mouth', which are:

- Brush your teeth twice a day with fluoride toothpaste and replace your toothbrush regularly

- Avoid sugary snacks between meals

- Visit the dentist regularly.

The launch included presentations from Dr Tony Jenner and Dr Gill Davies, both Specialists in Dental Public Health. Dr Jenner, also immediate past Deputy Chief Dental Officer for England, shared the conception of the Department of Health guidance document Delivering better oral health - an evidence-based toolkit for prevention. Dr Jenner also commented that 'Successive adult dental health surveys show the population of adults in England with no teeth has reduced dramatically. As we keep our teeth for longer, root caries also has the potential to become a serious problem that is difficult to treat.'

Dr Gill Davies then presented how the evidence in the toolkit can be put into practice, saying, 'Since the launch of the toolkit we have tended to focus on child prevention, leaving out prevention messages for gum disease and older adults. Adults who visit the dentist have an obvious opportunity to come into contact with a credible source giving appropriate advice. In fact, patients turn up and they expect to be advised by their clinician on what they should be doing to look after their own teeth. It's about maximising the effects of prevention and mobilising our clinical teams to make the most of this opportunity.'

Colgate Oral Health Month 2010 will run throughout September. Colgate is providing dental practices with packs which contain educational materials, motivational stickers, patient samples and materials to help dental teams drive the awareness of improved oral health by creating their own oral health month practice displays.

Interested dental practices can register to receive a Colgate Oral Health Month pack by telephoning 0161665 5881. One pack per practice will be delivered at the end of August, subject to availability.

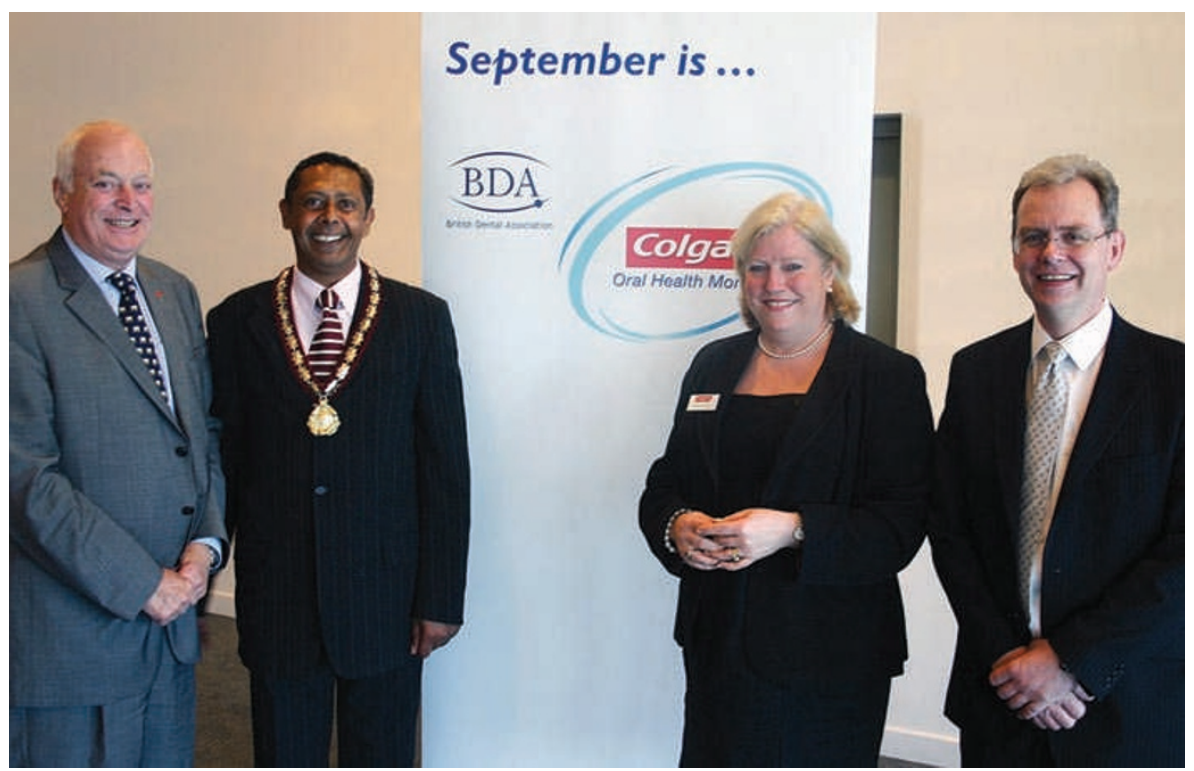

Left to right: Dr Paul Langmaid, Dr Amarjit Gill, Rhona Wilkie (Colgate) with Professor Damien Walmsley

ROYAL ARMY DENTAL TEAM ACE MOUNTAIN CHALLENGE

Five dental professionals from the Royal Army Dental Corps recently completed the gruelling Caledonian Challenge, one of Scotland's most challenging endurance events.

The aim of the event is to cover 54 miles in under 24 hours - the equivalent of completing two full marathons back to back with more ups and downs than two ascents of Ben Nevis - all in one go.

The event takes in part of the West Highland Way travelling through some of Scotland's most remote and rugged countryside including Glen Coe and Rannoch Moor.

The team, consisting of W01 Paul Dale, Private Navraj Rai, Lt Col Ewen McColl, Major Sean Greaves and Major Nick Gibbs, completed the event in 12 and a half hours, finishing fastest team of the 179 teams who took part. The team consisted of a dental support specialist, a dental technician and three dentists: truly a team effort.

As well as the challenge the team took part in a variety of outdoor pursuits prior to the event testing both leadership and team building in the Scottish mountains. In the process they raised over $£ 3,000$ for charity.

\section{INCAPACITY ASSESSMENT COURSE DEVELOPED}

The BDA's Scottish Salaried Dentists Committee has been involved in discussions which have led to NHS Education Scotland developing a course for dentists in the assessment of incapacity and will include learning outcomes.

The course will be in addition to the programme already provided by Napier University in Edinburgh. Initially the course will be piloted in Lanarkshire, but is likely to be rolled out to all dentists in Scotland in the future. 